\title{
Reliability-Based Optimum Design of Double Angle Web Cleats in Steel Portal Frames Using Genetic Algorithms
}

\author{
${ }^{1}$ Salisu Dahiru, ${ }^{2}$ Jibrin Mohammed Kaura and ${ }^{2}$ Idris Abubakar \\ ${ }^{1}$ Department of Civil Engineering Technology, Nuhu Bamalli Polytechnic, Zaria \\ ${ }^{2}$ Department of Civil Engineering, Ahmadu Bello University, Zaria
}

\begin{abstract}
It is no longer sufficient to design a system that perform the required task satisfactorily. It is essential to design the best system that is efficient, versatile, unique and cost-effective system. This study presents a developed computer program in Fortran 90 (Opticon 2011) for the optimum design of double angle web cleats in steel portal frames using evolutionary algorithms. The BS 5950 part 1, design criteria was adopted. The optimum design uses reliability technique and the uncertainties associated with the basic design variables were fully accommodated. The optimum design displayed a significant cost saving as compared with the JSC design values.
\end{abstract}

$\underline{\text { Key words: Genetic algorithms, optimum design, Opticon 2011, reliability index, double angle web cleat, Zaria }}$

\section{INTRODUCTION}

Simple connections are most frequently used in pin-jointed and braced structures in which the lateral stability is provided by diagonal bracing or other alternative structural elements. There are four main types of simple connections, namely:

- Angle web cleat (double and single)

- Flexible end plates

- Fin plates

- Gusset plates

In this study, reliability-based optimum design of double angle web cleat connection in simple steel portal frame was presented. A double angle web cleat connection comprised of two equal angles sections bolted to the web of the beam to be supported as shown earlier, the projection of $10 \mathrm{~mm}(\mathrm{BS}, 2000)$ of the web cleat beyond the end of the beam is to ensure that when the beam rotates the bottom flange does not bear on the supporting member. The positioning of the cleats near the top of the beam provides directional restraints to the compression flange. When this arrangement is used in addition to a length of cleat equals approximately, $60 \%$ of the beam depth the end of the beam can be assumed to have torsional restrain (BS, 2000).

Reliability-based optimum design: In the highly competitive world of today, it is no longer sufficient to design a system that perform the required task satisfactorily. It is essential to design a efficient, versatile, unique and cost-effective system (Arora, 1989). Best systems are achieved through optimum design. On the other hand for practical optimum design, reliability-based techniques are getting increasingly popular (Platt and Mtenga, 2006; Hall, 2005; Melchers, 1999; Ditlevsen and Madsen, 2005) due to the uncertainties involved in realizing design variables and stochasticities involved in variable properties.

The optimum design of double angle web cleats presented in this study is based on reliability principles, implemented using first order reliability-based genetic algorithms GA, through a computer program (Opticon 2011) developed using Fortran 90.

Genetic algorithms: Many human inventions were inspired by nature. Genetic algorithm is a search method that simulates the principle of evolution inspired by Darwin's evolutionary theory. This technique was inspired by the way living things evolved in to more successful organisms in nature. The main idea is survival of the fittest, also known as natural selection.

\section{MATERIALS AND METHODS}

Preamable: Genetic algorithms encode a potential solution to specific problem on a simple chromosome-like data structure. These particular branch of Artificial Intelligence (AI) was inspired by the way living things

Corresponding Author: Salisu Dahiru, Department of Civil Engineering Technology, Nuhu Bamalli Polytechnic, Zaria 
evolves into a more successful organisms in nature. The main idea is survival of the fittest. Chromosome is a long complicated thread of DNA (Deoxyribonucleic Acid). Hereditary factors that determine particular traits of an individual are strung along the length of these chromosomes, like bids on a necklace. Each trait is coded by some combination of DNA (there are four bases, A (Adenine), C (Cytosine), T (Thymine) and G (Guanine)). Like an alphabet in a language, meaningful combination of the bases produces specific instructions to the cells. Changes occur during reproduction, the chromosomes from the parent exchange randomly by a process called crossover.

Therefore, the offspring exhibits some traits of the father and some traits of the mother. A rare process called mutation also changes some traits. Sometimes, a transition may occur during copying of chromosome (Mitosis), the parent cell may have -A-C-G-C-T- but something unusual may occur and changes the new cell to -A-C-T-C-Tusually this result produce a poor specie but with time a better specie is produced. The major steps involved in genetic algorithms are:

- The generation of a population of solution

- Finding the objective function

- Fitness function

- Application of genetic operators

In this particular present problem, two parent chromosomes were considered, namely the angle cleat and the bolt. Each parent chromosome has a string of genes which when combined together by the genetic operators will produce an individual connection having some traits of the father and some of the mother. Considering the cleat angle, it has random variable (genes) like, strength, thickness and length $\left(\mathrm{P}_{\mathrm{y}}, \mathrm{t}_{\mathrm{p}}, \mathrm{D}_{\mathrm{p}}\right)$, the bolt itself contains random variables like, number of bolts, the size of bolt (area, diameter), the strength of bolt (grade), i.e., bearing, shearing and tensile strengths. Random mixing of these variables will yield an individual connection.

Objective function: An efficient connection is considered in this study as the one that provides an approximately equal safety index to the various modes of failures as a result, the existence of any super-predominant failure mode will be eliminated. This means regulating and moderating safety indices of the different mode. Here, First Order Reliability Method (FORM) was employed in the assessment of the safety indices of the different failure constraints for each individual connection which will serve as bases in estimating its quality. Taking $D_{p}$ (angle length), D (Diameter of bolt), $\mathrm{F}_{\mathrm{s}}$ (shear strength of bolt), $F_{b s}$ (steel angle/beam bearing strength), W (load from supported beam) as random variables in the reliability assessment, assumed to be approximately normally distributed with coefficients of variations $5,5,15$, 15 and $10 \%$, respectively. The objective function is given by:

$$
\text { OBJf }=\Sigma \beta_{i}
$$

Where, $\beta_{\mathrm{i}}$ is the reliability index of the ith failure mode.

Fitness function: A fitness function was first derived from the objective function and used in successive genetic operations. Fitness in biological sense is quality value which is a measure of the reproductive efficiency of a chromosome.

This means that individuals with higher fitness value will have higher probability of being among the final generation (results). Fitness function in this particular situation was formulated to account for two problems:

- The regulation or minimization of surplus safety margin

- Identify individual connections with approximately uniform safety index so as to avoid a existence of a super-predominant failure mode

Fitness $=1 /(1+\log (\mathrm{OBJfx}))+[(1 /(1+\log (\mathrm{CV}))-0.2]$

Where:

$$
\begin{gathered}
\mathrm{CV}=\text { Mean } / \mathrm{SD} \times 100 \\
\text { Mean }=\frac{\Sigma \beta_{\mathrm{i}}}{\mathrm{N}} \\
\mathrm{SD}=\frac{\Sigma\left(\beta_{\mathrm{i}}-\text { mean }\right)^{2}}{\mathrm{~N}-1}
\end{gathered}
$$

$\mathrm{N}$ is the number of possible modes of failure.

Crossover and mutation operators: Crossover is the primary operator in GAs and the key to their success (Wang and Ghosn, 2005; Deng et al., 2005). The two strings participating in the crossover operation are known as parent stings and resulting strings are termed children 
strings. The operator is used to combine two strings to get a better string. In reproduction, good strings in a population are probabilistic ally assigned larger number of copies and a mating pool is formed. Mutation adds new information in a random way to the genetic search process and ultimately helps to avoid getting trapped within local optima. It is an operator that introduces diversity in the population whenever the population tends to become homogeneous the repeated use of reproduction and crossover operators.

Application of these operators on the parent chromosomes creates an individual. This new individual yield solution that might be the or closer the optimum solution.

The value of the objective function is determined, this express the fitness of the new individual. This complete cycle of genetic algorithm is called generation. In each generation if the solution is improved, it is stored among the best solutions.

Selection: The genetic algorithm selection process selects individuals for reproduction or as final optimum solution. The selection is based on the individuals' fitness, two selection technique are common. In this research, a selection method called Roulette-wheel selection was implemented.

Constraints: The program Opticon 2011 was built and run under many constraints provided in BS (2000). These are:

- The bolt spacing $\geq 2.5$, the diameter size

- The edge clearance $\geq 1.25$, bolt's diameter (for a rolled machine flame cut, sawn or plane edge (Table 1) and $\geq 1.4$ bolt diameter (for a sheared or hand flame cut edge)

- $\mathrm{Gi}(\mathrm{x}) \geq 0$

- $\beta_{1} \geq$ TASIU
TASIU is a self adjustable factor which can be automated to run the optimization at different limited safety indices. Figure 1 shows the flowchart of the basic GA operation.

Failure modes of the double angle web cleat: The following failure modes were considered in the program development:

- Beam-web bolts shear failure

- Supporting column flange bolts shear failure

- Cleat shear failure

- Beam-web cleat bearing failure

- Column-flange cleat bearing failure

- Beam-web block shear failure

- Beam-web bearing failure

The resistance models against each of the seven failure modes were taken from BS (2000). Reliability

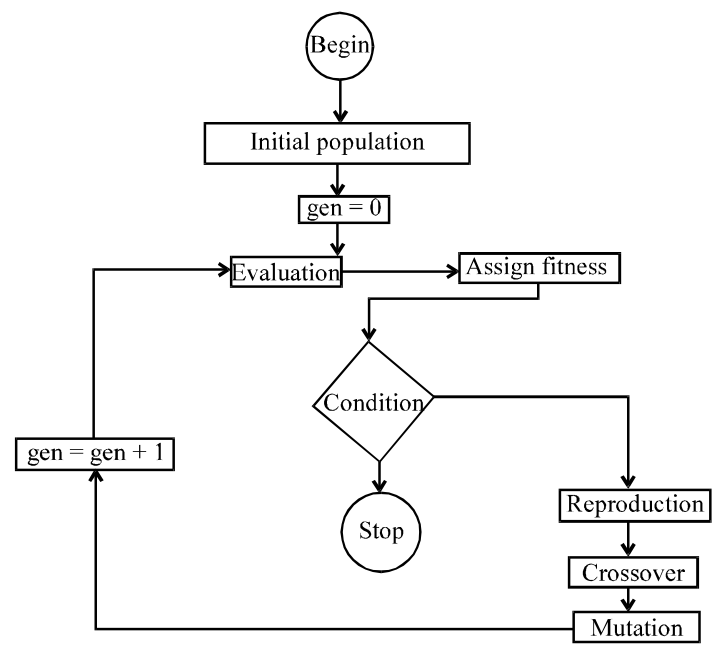

Fig. 1: Flowchart of working principle of a Genetic Algorithm (GA)

Table 1: Comparison of JSC and Opticon 2011 design

\begin{tabular}{|c|c|c|c|}
\hline \multirow[b]{2}{*}{$\underline{\text { Parameters }}$} & \multirow[b]{2}{*}{$\begin{array}{l}\text { JSC manual (double } \\
\text { angle web cleat) CC6 }\end{array}$} & \multicolumn{2}{|c|}{ Opticon 2011 optimized design } \\
\hline & & Opticon1 & Opticon2 \\
\hline End load on the connection $(\mathrm{kN})$ & 465.0 & 465.0 & 465.0 \\
\hline Total number of bolts recommended & 18 & 18 & 18 \\
\hline Grade and size of bolt & Grade $8.8 \mathrm{M} 20$ & Grade $8.8 \mathrm{M} 16$ & Grade $8.8 \mathrm{M} 20$ \\
\hline Recommended angle size & $90 \times 90 \times 10$ & $90 \times 90 \times 8$ & $90 \times 90 \times 10$ \\
\hline Recommended angle length (mm) & 430.0 & 319.0 & 351 \\
\hline Steel grade & $\mathrm{S} 275$ & $\mathrm{~S} 275$ & $\mathrm{~S} 275$ \\
\hline Mass of steel angle incorporated $(\mathrm{kg})$ & 11.524 & 6.954 & 9.406 \\
\hline Variation in safety indices (\%) & 40 & 21 & 36 \\
\hline Maximum tensile force possible/resistance $(\mathrm{kN})$ & $465.0 / 1116$ & $465.0 / 466.2$ & $465.0 / 602.2$ \\
\hline Connection safety index & 3.5 & 1.4 & 3.4 \\
\hline Save in cost $(\%)$ & 39.7 & 18.4 & - \\
\hline
\end{tabular}




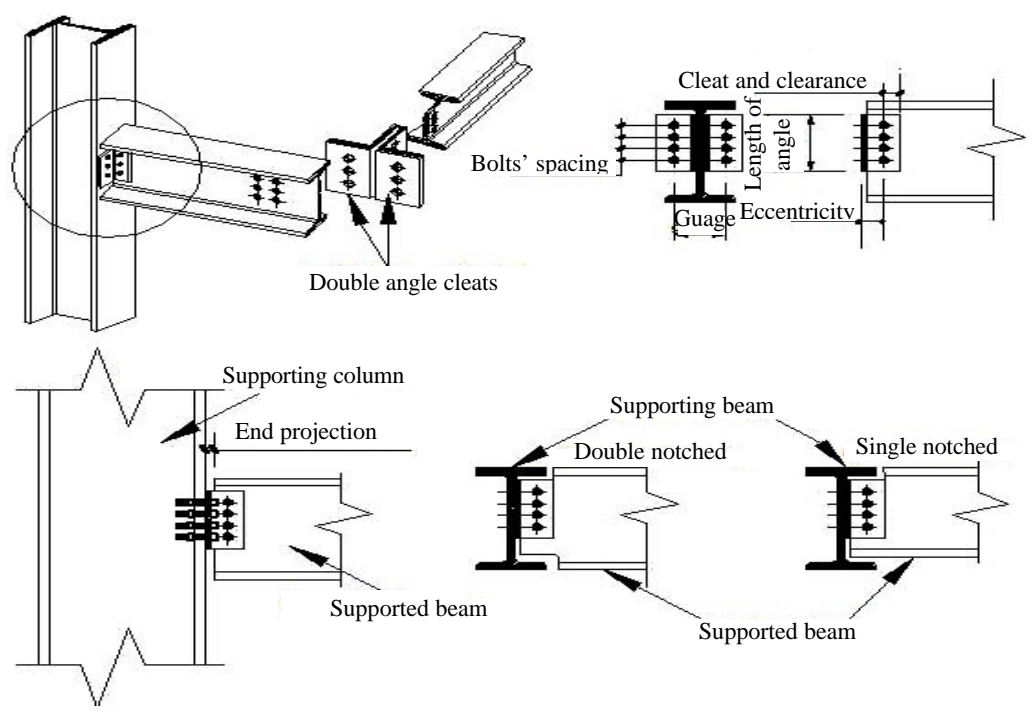

Fig. 2: Typical double angle web cleat

functions were formulated for each failure modes and fully incorporated in the program (Opticon). Figure 2 shows the configuration of a typical double angle web cleat connection.

\section{RESULTS AND DISCUSSION}

A computer program in Fortran 90 (Opticon 2011) was developed to implement the optimum design of double angle web cleat based on BS (2000). The program requires the following information to run:

Output file name: This is the name of the final output file, it can not exceed 16 characters.

Load on the supported beam: The factored design load in Kilo-Newton per meter $\left(\mathrm{KN} \mathrm{m}^{-1}\right)$ that is acting on the supported beam.

Length of beam: The length in meters of the supported beam.

Depth: The depth of the supported beam, i.e. (D) in millimeters ( $\mathrm{mm}$ ) from sections properties table.

Thickness of web: The supported beam web thickness in $\mathrm{mm}$ from the steel section properties table.

Steel grade: The grade of steel in use in Newton per square millimeter $\left(\mathrm{N} \mathrm{mm}^{-2}\right)$.

1 dimension of equal angle: The dimension of equal angle desired or available, mostly it is $90 \times 90(90 \mathrm{~mm})$ or $100 \times 100$ $(100 \mathrm{~mm})$. The dimensions are in millimeters.
1 dimension of equal angle: The dimension of equal angle desired or available, mostly it is $90 \times 90(90 \mathrm{~mm})$ or $100 \times 100$ $(100 \mathrm{~mm})$. The dimensions are in millimeters.

Safety index: The desired safety index to which the program is to be run. It must be a positive real number lying between 0-5 depending on the supported load. A value of zero implies satisfying the design code with the minimum safety merging possible. The higher the safety index, the greater the safety margin but not necessary higher efficiency. A value will be recommended at the last chapter of this study. The output is a population of 5 best designs obtained at that particular safety index to which the program is run. The five different designs is necessary in order to provide designer with options so that, he can select the design that will suit his particular need according to available resources and degree of safety necessary. The outputs include:

Individual number: This identifies the various individual designs from 1-5 e.g., the first design will be individual 1, the second will be individual 2 , etc., up to individual 5 . It has nothing to do with preference of selection.

Limited safety index: Limited safety index is the reliability index to which the optimization is performed. It implies that no single failure mode has its safety index below this value.

Overall fitness: This is a real number which determines the preference of selection, the higher the overall fitness the higher the probability of the individual to be part of the final results population. It is the sum of cost fit and safety fit. 
Cost fit: This indicates the relative closeness of the given design to the limited safety index. The design with higher cost fit is the one with least excess or surplus safety margin relative to the limited safety index.

Safety fit: This indicates the uniformity of the various safety indices of the different failure modes. The individual design with the highest safety fit will be the most efficient design which could reach its full capacity without a local failure. Local failure means failure due to one or two failure modes with the rest of the failure modes not reaching even close to their capacity.

Number and sizes of bolt: The number of bolt is the total number of bolts in the connection. There is provision for combination of different sizes of bolt if two different sizes are involve the total number of bolts will be the sum of the 2 different sizes, this should be divided by three to make the three columns of bolts present in a double angle web cleat single line connection.

In case of two different bolt sizes, the smaller bolts should be located at the middle within the column, i.e., the bigger sizes should be located at the outer bounds of the bolts line because that is where the maximum stress (tensile/rotational) exist.

Grade: The grade is the designated bolts grade of the connection which are commercially available named in BS (2000).

Angle length: This is the length of angle in millimeter that is to be in cooperated in the connection to accommodate the given number of bolts at the stated spacing.

Spacing of bolt: This is the spacing at which the bolts should be arranged.

Angle size: The size of equal angle steel section from the steel section properties table.

Load eccentricity: The distance from the center of supported beam bolt column to the supporting column flange or beam web.

Cleat end clearance: This is the distance from where the eccentricity in the supported beam stops to the edge of the angle cleat.

Mass of incorporated steel angle: This is the mass of steel angle required in the connection, a function of the angle length and its thickness.
Tying capacity: The minimum tensile stress that the connection can withstand incase the connection is subjected to direct or indirect tension also known as the integrity of the connection.

Gauge mark: The separation of the supporting columnflange or beam-web 2 column of bolts.

Connection equivalent safety index: This is the overall reliability index of the whole connection, i.e., a measure of one's design confidence against failure, it implies the higher the reliability index the far away the connection is from failure zone.

But this does not necessarily signifies corresponding higher efficiency as it is observed that the higher the reliability index the higher the variation among the various safety indices of the different failure modes Appendix A is a typical output of the program.

Numerical example: A certain double angle web cleat connection has been designed from standard tabulated double angle connection (Joint in Steel Construction manual JSC), this manual contain various standard designs for different types of connections, e.g., flexible end plate, fin plate, double and single angle connections, moment connections, etc., with their various capacity. The

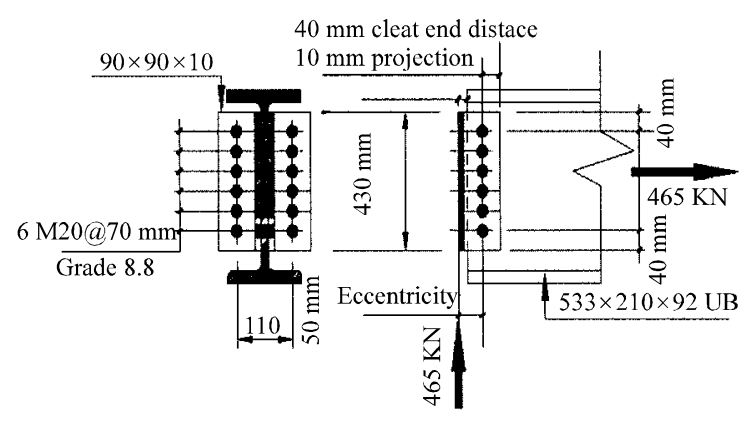

Fig. 3: Connection arrangement CC6

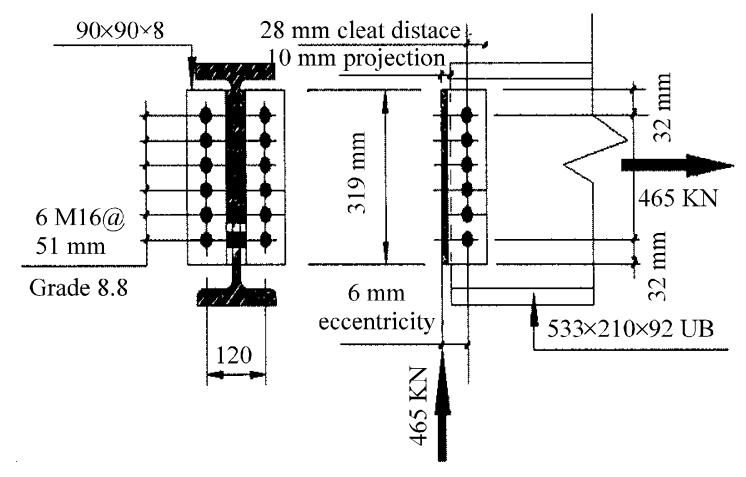

Fig. 4: Connection arrangement Opticon1 


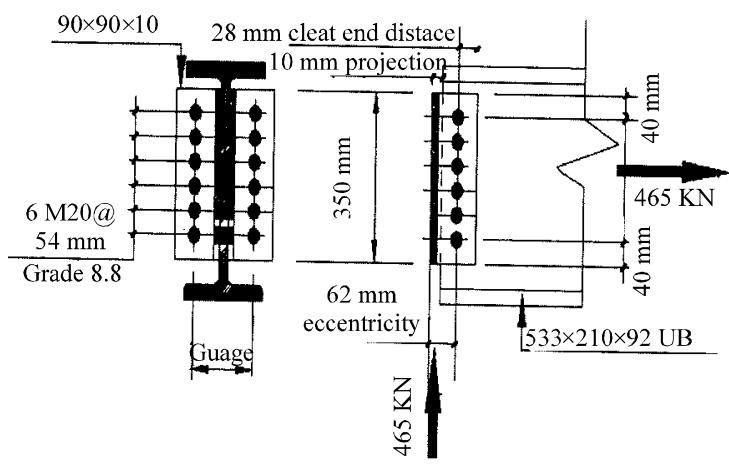

Fig. 5: Connection arrangement Opticon 2

connection is to transmit an end shear load of $465 \mathrm{KN}$ with an equivalent maximum possible tensile load of $465 \mathrm{KN}$ (assumed). The supported beam size is $533 \times 210 \times 92 \mathrm{UB}$, Grade $\mathrm{S} 275$ ( $\mathrm{t}=10.2 \mathrm{~mm}, \mathrm{D}=533.1 \mathrm{~mm}$, $\mathrm{W}_{\text {eq }}=77.5 \mathrm{KN} \mathrm{m}^{-1}$, span $=12 \mathrm{~m}$ ).

The code name of the chosen connection in the JSC manual is CC6. A tabular comparison between the JSC design and corresponding results obtained using Opticon 2011 is shown in Table 1. Detail of the design is shown in Fig. 3-5.

\section{CONCLUSION}

A computer program for reliability-based optimum design of double angle web cleat in simple portal frames in Fortran 90 was presented in this study. The connection design with the program shows significant cost saving as showed in Table 1. This is a welcome development as cost of connections in steel frame structures constitute significant portion of the cost of the frames. The optimum design was implemented using probabilistic method. This implied that uncertainties in the design variables of the connection were accommodated. The program therefore, address both safety and economy in the optimization process.

\section{RECOMMENDATIONS}

It is recommended in this study that higher safety index should not be the only target in connection design, the efficiency or effectiveness of the connection should also be given appropriate consideration by eliminating variability in the various safety indices. This is why, we need optimization tools like Opticon 2011.

\section{APPENDIX A}

\section{Sample Output of the Program:}

Individual 1 , Limited safety index $=2.00$

Connection equivalent safety index $=1.67$

Overall fitness $=0.566417$

Cost fit $=0.430907 ;$ Safety fit $=0.135510$
18 no. of M16

Plus

0 no. of M0

Grade 8.8

Angle length $(\mathrm{mm})=351.00$ Bolt spacing $(\mathrm{mm})=57.40$

Angle size is 2 no. of $90 \times 90 \times 8$

Load ecentricity $(\mathrm{mm})=62.00$ Cleat end clearance $(\mathrm{mm})=28.00$

Mass of incoperated steel angle in gram $(\mathrm{g})=7651.80$

Tying capacity $(\mathrm{KN})=534.60$

Gauge mark $(\mathrm{mm})=120.00$

Individual 3, Limited safety index $=2.00$

Connection equivalent safety index $=1.64$

Overall fittness $=0.571397$

Cost fit $=0.432095 ; \quad$ Safety fit $=0.139303$

18 no. of M16

Plus

0 no. of Mo

Grade 8.8

Angle length $(\mathrm{mm})=341.00$ Bolt spacing $(\mathrm{mm})=55.40$

Angle size is 2 no. of $90 \times 90 \times 8$

Load ecentricity $(\mathrm{mm})=60.00$ Cleat end clearance $(\mathrm{mm})=30.00$

Mass of incoperated steel angle in gram $(g)=7433.80$

Tying capacity $(\mathrm{KN})=512.60$

Gauge mark $(\mathrm{mm})=120.00$

Individual 4, Limited safety index $=2.00$

Connection equivalent safety index $=1.51$

Overall fitness $=0.562674$

Cost fit $=0.434123 ; \quad$ Safety fit $=0.128551$

18 no. of M16

Plus

0 no. of M0

Grade 8.8

Angle length $(\mathrm{mm})=330.00$ Bolt spacing $(\mathrm{mm})=53.20$

Angle size is 2 no. of $90 \times 90 \times 8$

Load ecentricity $(\mathrm{mm})=58.00$ Cleat end clearance $(\mathrm{mm})=32.00$

Mass of incoperated steel angle in gram $(\mathrm{g})=7194.00$

Tying capacity $(\mathrm{KN})=488.40$

Gauge mark $(\mathrm{mm})=120.00$

Individual 5, Limited safety index $=2.00$

Connection equivalent safety index $=2.01$

Overall fitness $=0.336458$

Cost fit $=0.358443 ;$ Safety fit $=-0.021985$

9 no. of M22

Plus

9 no. of $\mathrm{M} 20$

Grade 0.0

Angle length $(\mathrm{mm})=319.00$ Bolt spacing $(\mathrm{mm})=55.80$

Angle size is 2 no. of $90 \times 90 \times 12$

Load ecentricity $(\mathrm{mm})=58.00$ Cleat end clearance $(\mathrm{mm})=32.00$

Mass of incoperated steel angle in gram $(\mathrm{g})=10144.20$

Tying capacity $(\mathrm{KN})=298.65$

Gauge mark $(\mathrm{mm})=120.00$

Note: Grade 0.0 stands for general grade

\section{REFERENCES}

Arora, J.S., 1989. Introduction to Optimum Design. McGraw-Hill International, New York.

BS, 2000. British steel design code 5950. British Standard Institute, UK.

Deng, L., M. Ghosn and S. Shao, 2005. Development of a shredding genetic algorithm for structural reliability. Struct. Saf., 27: 113-131.

Ditlevsen, O. and H. Madsen, 2005. Structural Reliability Methods. 1st Edn., John Wiley and Sons, New York, ISBN: 0-471-96086-1. 
Hall, S., 2005. Genetic algorithm based optimized moment steel frames. M.Sc. Thesis, Civil Engineering, North Carolina State University.

Melchers, R.E., 1999. Structural Reliability Analysis and Prediction. Jhon Wiley and Sons, New York.
Platt, B.S. and P.V. Mtenga, 2006. Parametric optimization of steel floor system cost using evolver. M.Sc. Thesis, Department of Civil Engineering, Florida State University.

Wang, J. and M. Ghosn, 2005. Linkage-shredding genetic algorithm for reliability assessment of structural systems. Struct. Saf., 27: 49-72. 